\title{
A Welfare Analysis on GM Crop Market Structures and Existing Regulations
}

\author{
Linda Lee ${ }^{1}$ and Aaron Giesbrecht ${ }^{\#}$ \\ ${ }^{1}$ Sentinel Secondary School, Vancouver, BC, Canada \\ \#Advisor
}

\section{ABSTRACT}

Since their introduction in 1994, genetically modified (GM) crops have become a major sector of the agricultural industry in developing and developed countries. Despite this, many economic concerns have arisen regarding how governments regulate GM crops. These concerns have caused countries to ban GM crop usage, which has proven to be detrimental for national and international economies. This paper outlines the economic advantages of GM crop production and usage and surveys the current inefficiencies in the regulation of GM crops through a review on existing literature. It notes the increased farming efficiency, cost effectiveness, and rise in income for developing countries resulting from GM crop production and usage. It then considers why many of the listed potential benefits are unrealized, particularly due to the excessive market power given to GM seed producers, high barriers of entry into the GM market due to biosafety procedures, utility patents, and international trade asymmetries. Finally, the discussion section of the paper poses potential solutions by describing methods to efficiently regulate GM crops and suggesting possible areas of further research. The objective of this paper is to inform readers with minimal economic understanding of the potential economic benefits of GM crops and aid them in recognizing the optimal ways to regulate them.

\section{Introduction}

Genetically modified organisms (GMOs) have garnered immense popularity since their introduction in the late 1900s as agricultural industries struggle to feed a rapidly rising population. With the global GMO crop market on track to reaching \$37.46 billion USD by the end of 2027 (Coherent Market Insights, 2020), GM crops have great influence on the global economy. Due to the reliance on the technology to maintain an adequate food supply and a stable economy, a limit on them would be costly, especially in countries where food scarcity remains a pressing issue. However, due to its great influence, effective regulations must be implemented to maximize consumer and producer welfare within the GM crop market. Economic studies on GM crops show that current GM crop regulations require revision and improvement to realize the potential benefits they could pose to developed and developing countries. With current regulations, utility and biotechnology patents provide few GM seed companies with exceeding amounts of market power, which has resulted in a number of problems, one being overpriced GM seeds. Along with patents, biosafety regulations have created high barriers of entry into the GM seed market, proving costly for small-scale farmers and aggravating economic inequality. Global asymmetries in the approval of GM crops have complicated international trade efforts, preventing the potential benefits of cheap labour from being realized. Therefore, suggestions for possible changes in regulations entails limiting the market power currently possessed by GM seed producers to increase consumer welfare and promoting the harmonization of international trade. There are certainly limitations to these solutions, such as legal and political issues, but regardless, further economic research must be conducted, such as providing more accurate estimates of potential externalities and the market concentration of GM seeds to find a better method of regulation. Accordingly, this paper first addresses the efficiency presented by GM crops, before discussing the 
drawbacks of current GM crop regulations, potential solutions for the issue posed and, finally, suggestions for further research.

\section{Economic Benefits of GM Crops}

\section{Farm Efficiency at Firm Level}

Genetically modified crops increase farmer profitability by raising yield and decreasing pesticide expenditures. Based on a study of field trials published in the PLOS ONE journal, a switch from non-GM to GM crops delivers "average profit gains [of] 69\%" for farmers (Klümper \& Qaim, 2014). Any limit on GM farming methods would hinder farmers' expansion efforts or force them to downsize operations, potentially decreasing their quality of life due to lower earnings. The rise in profit generated by GM crops comes from increased productivity. An International Service for the Acquisition of Agri-biotech Applications (ISAAA) survey of 470 GMO and non-GMO corn farmers in the Philippines shows the average yield of Bacillus thuringiensis (Bt) corn, a type of pest-resistant GM crop, farms there is " 4,850 $\mathrm{kg} / \mathrm{ha}$ as compared to only 3,610 kg/ha for the non-users" (Yorobe. Jr \& Quicoy, 2006, p. 260). As marginal productivity, the output received per unit of input, increases due to yield gains, input costs are lowered, hence net income is directly increased due to a higher quantity in exchange to a lower price (Fig. 1).

\section{Supply Shift in Market}

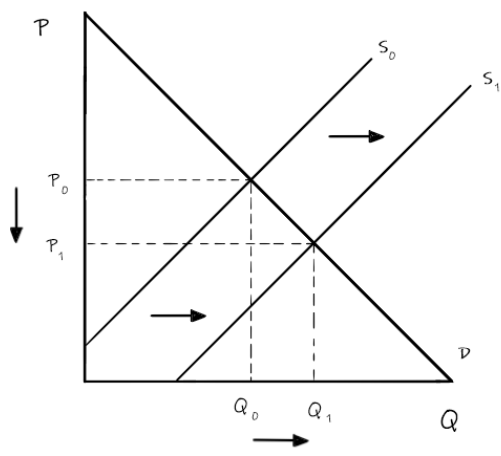

Figure 1. Effect of Supply Shift in GM Crop Seed Market on Prices of GM Seeds

\section{Cost Effectiveness from Elimination of Input Costs}

Besides improving farming efficiency, GM crops are also cost effective. For example, the ISAAA revealed that in pest-resistant corn in the Philippines, "an additional profit of PhP 10,132 [Philippine Pesos] per hectare" was earned from "a reduction in insecticide expenditures of 60\%" (Yorobe. Jr \& Quicoy, 2006, p. 266). This benefit is similar to how farmers gain from higher productivity, as they can save capital through the elimination of an expensive input cost. Apart from GMO farmers, non-GMO farmers benefit from a market adjustment too. Klümper and Qaim (2014), agricultural economics researchers at the University of Goettingen, discovered that on average, "GM crops have reduced [overall] pesticide cost by 39\%", signifying that spending is lowered for all farmers (whether GMO or organic) relying on pesticides, because of price changes in the pesticide market. Consequently, all farmers would suffer from limits on GMOs, because they would need to increase labour and operational expenses to maintain levels of production. 


\title{
Improvements in Quality of Life for Developing Countries
}

Although it is regarded that only developed countries reap the benefits of GM crops, they present high investment returns and rural income in developing countries too (James, 2013). The Grains Research and Development Corporation (GRDC) of the Australian government claims farmers in developing countries receive \$5.15 in extra income for every $\$ 1$ invested in GM seeds (Mullot, 2017). Thus, a rise in investment returns alleviates poverty and enables poorer farmers to earn a stable income. Further, GM crops especially benefit disadvantaged farmers, since more drastic improvements are seen from old technologies. To illustrate the extent of this, PLOS ONE reports that "yield gains of GM crops are 14 percentage points higher in developing countries than in developed countries" (Klümper \& Qaim, 2014). Yield gains increase food supply, which is vital in developing countries where famine is prevalent. Moreover, according to the United States Department of Agriculture, herbicide tolerant soybeans "[free] up management time for. . . off-farm income-generating activities" (Fernandez-Cornejo et al., 2014, p. 22). GM crops promote economic equality by allowing indigent farmers to work another job to cover expenses; because of this, efficient time management is crucial to poorer farmers. A professor in the Department of Agricultural and Resource Economics at the University of Saskatchewan explains, "Bt cotton adoption in India raised vulnerable household incomes (those defined as living on less than $\$ 2 /$ day) by $134 \%$ " (Smyth, 2019). Based on India, one of the world's largest agricultural producers and a developing country, it can be further supported that GM crops narrow the gap between the wealthy and the poor.

\section{Drawbacks of Market Inefficiencies and Current GM Crop Regulations}

\author{
Biotechnology Patents and Market Power
}

While GM crops are economically beneficial for farmers, economic conflicts between GMO farmers and biotechnology seed companies result in unfavorable compromises. As stated by the National Academies of Sciences, Engineering, and Medicine, "[t]he seed-price index has exceeded the average index of prices paid by U.S. farmers by nearly 30 percent since the introduction of GE seeds in 1996" (National Research Council, 2010, p. 146). Since seeds are a production cost for farmers, a rise in their prices means decreased net benefits, suggesting higher barriers of entry into the GMO industry, and consequently, less farmers profiting from selling these crops. Matin Qaim (2009) comments that seed prices have risen because GM crops are "commercialized by private companies" who own "more than $75 \%$ of all patents in agricultural biotechnology" and charge a "technology fee" on seeds. Patents on GM seeds enable the creation of oligopolies and monopolies by biotechnology companies that take advantage of their market power and the inelastic demand for GM seeds to markup seed prices, resulting in supernormal economic profits (Fig. 2). Indeed, the degree to which prices are raised is financially disastrous for farmers, as GM seed producer surplus increases at the expense of consumer (farmer) surplus. Ideally, if the GM seed market were in a perfect competition market (Fig. 3), total surplus would be maximized, thus, reasonable prices for farmers would be set where price equaled marginal cost and at firms' minimum average total cost. Qaim notes, "[s]everal early studies for HT soybeans in the United States showed that the fee was of a similar magnitude or sometimes higher than the average cost reduction, so that gross margin effects were small or partly negative." Since GM technology creation is so prohibitive, prices are inflated so much that the cost of growing GM crops may outweigh the economic benefits. Raised prices are particularly harmful for farmers, since patents prevent the replanting of GM seeds, meaning they have to purchase new seeds every season. In addition, these biotechnology patents hinder market competition, reinforcing monopoly control in the GM seed market. One notable example is the Bowman vs Monsanto case; in 2013, Monsanto, a major producer of herbicide resistant GM seeds "sued Vernon Hugh Bowman, a soybean farmer, for patent infringement", as Bowman replanted herbicide resistant commodity seeds. Thus, patents provide Monsanto with a "legal monopoly", protecting them from being challenged by "commodity sellers" (Caruvana \& Holton-Basaldua, 2013). Hence, without 
monopoly regulations, GM crop profits would be exploited by few biotechnology companies, while the majority of society, including farmers and other GM seed sellers, would take the burden.

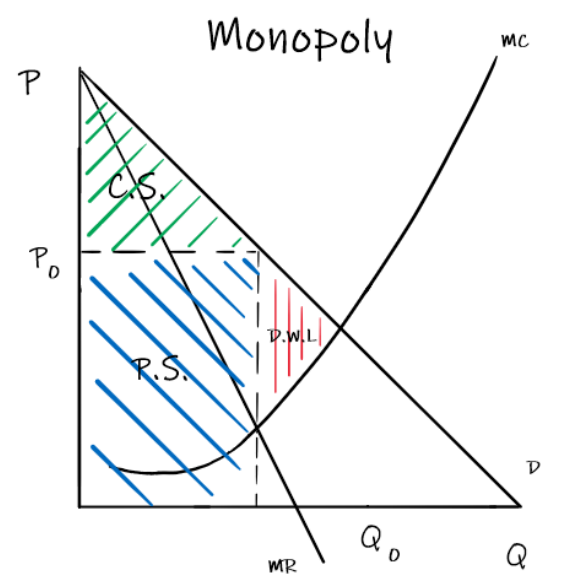

Figure 2. Consumer and Producer Surplus in Monopoly Market

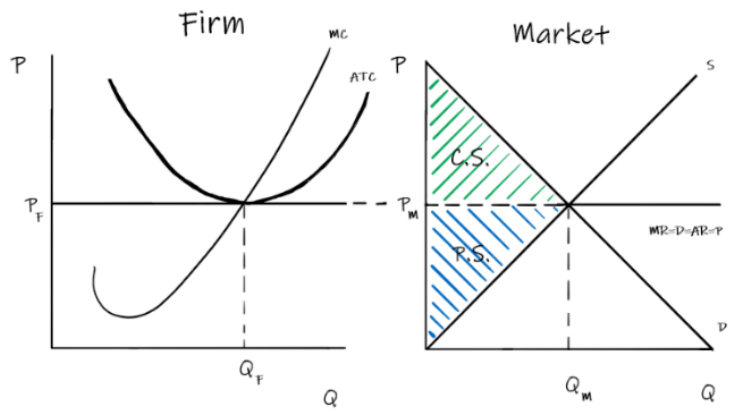

Figure 3. Consumer and Producer Surplus in Perfect Competition Firm and Market

\section{Biosafety Compliance and Delay Costs}

The economic benefits of GM crops are not only lost from biotechnology company control, as they are also lost through biosafety regulations. Biosafety regulatory cost barriers and delays in regulatory procedures are detrimental to both the farmers and consumers of GM crops. GM Crops \& Food, published in Taylor \& Francis Online, states, "it has been almost impossible so far for GM crops developed by small and medium-sized enterprises. . to reach the market" (Whelan \& Lema, 2017). Economic inequality is aggravated as smaller GM farms cannot afford to comply with regulations to enter the market and earn through biotechnology usage. Even for farmers who can afford the fixed cost, according to the Journal of Agrobiotechnology Management and Economics, the total cost for compliance with biosafety regulations in the US ranges from 3-12 million USD (Bayer et al., 2010). There is a high opportunity cost in complying with these regulations, since farmers could use this capital to conduct profit-generating activities, such as growing more crops instead. Apart from the financial barrier to entering the market, farmers incur costs from delays in these procedures. The Graduate School of Public Policy at the University of Saskatchewan informs that "in 2005, a two-year delay in the approval of Bt cotton in India led to aggregate losses to farmers alone of more than $\$ 100$ 
million" (Phillips, 2014). Overwhelming amounts of food production, not to mention farmer income, are lost through these procedures. From this perspective, less production of GM crops would create farmer equality and a more efficient market structure by reducing capital put towards regulations and investing in food production instead.

\section{International Trade Barriers and Global Asymmetries}

Not only are the farmers of GM crops financially hurt from regulatory policies within their country, trade barriers caused by global regulatory asymmetries also contribute to the decrease in economic benefits of GM crops for both importing and exporting countries. According to Stanford University, the country importing the cheaper genetically modified food is often at an advantage (Hammer, n.d.), likely because the cost of labour is less in exporting countries, but various import bans are in place that prevent these benefits from being realized (Qaim, 2009). Specifically, farmers of exporting countries and consumers of importing countries are at a disadvantage the most. The book, The Impact of Genetically Engineered Crops on Farm Sustainability in the United States, claims that a "moratorium on the export of GE crops to the EU will quadruple the losses to U.S. farmers. . [and] is estimated to reduce the income of North American farmers by 0.5 percent" (National Research Council, 2010, p. 163). This decrease in income would likely be observed due to a decrease in demand for workers in the GM crop production industry since the demand for GM crops would be lowered. For example, the financial impacts observed due to a ban on American exports of corn and soybeans by the European Union is the epitome of the toll export bans place on a country's economy. In 1996, American exports of these crops totaled $\$ 3$ billion, however, in 2000, exports dropped to $\$ 1$ billion (Kruft, 2001), thus America's gross domestic product directly decreased through the decrease in exports.

Import bans reduce the potential economic welfare of US farmers, but consumers of importers, such as the European Union, suffer from a loss too. Through international trade, domestic prices are lowered for consumers due to specialization and improved resource allocation, resulting in lowered opportunity costs and increased production capacity. Without it, any single country has restrictions on how many goods it can produce, based on its level of technology and resources. In addition, global regulatory asymmetries, such as the disapproval of a GM product overseas may complicate international trade. An implication of this is the lost potential to alleviate public health problems in countries that have banned the product. For instance, the distribution of GM rice, known as "golden rice", containing many essential vitamins and nutrients, has not been approved in Bangladesh (Whelan \& Lema, 2006), thus consumers are not able to receive its health benefits because of regulatory asymmetries.

\section{Discussion}

\section{Solutions and Limitations}

GM crops provide the potential to improve global agricultural and labour economies because of the high productivity and efficiency it presents to the farming process. Therefore, it would be costly to place a limit or ban on them. Instead, the potential benefits of GM crops may be fully maximized with some, or a combination of, possible solutions, including implementing GM seed price-caps to reduce biotechnology market power, easing market entry of firms through the lifting of utility patents, and creating global competition and/or bilateral trade agreements. Imposing a GM seed price ceiling in the GM seed market would result in lower prices at a higher quantity and increase consumer surplus, as it would reduce market power. Contrary to the nature of certain market structures, such as perfect competition markets, imposing a price ceiling would result in decreased deadweight loss, since the quantity is not set where marginal revenue and marginal cost intersect, rather, it is set where the price ceiling meets the demand curve (Fig. 4). According to The Economic Times, the government of India implemented a Cotton Seed Price Control Order on Bt 
cotton seeds in 2015 to "support distressed farmers" in times of unfavorable farming conditions (Sally, 2016), capping GM cotton prices by as much as 300 rupees per packet (Bhardwaj, 2018). Although this solution benefits consumers of GM foods, many GM seed companies, such as Monsanto, have claimed this action "overrides existing private bilateral commercial contracts" (Sally, 2016).

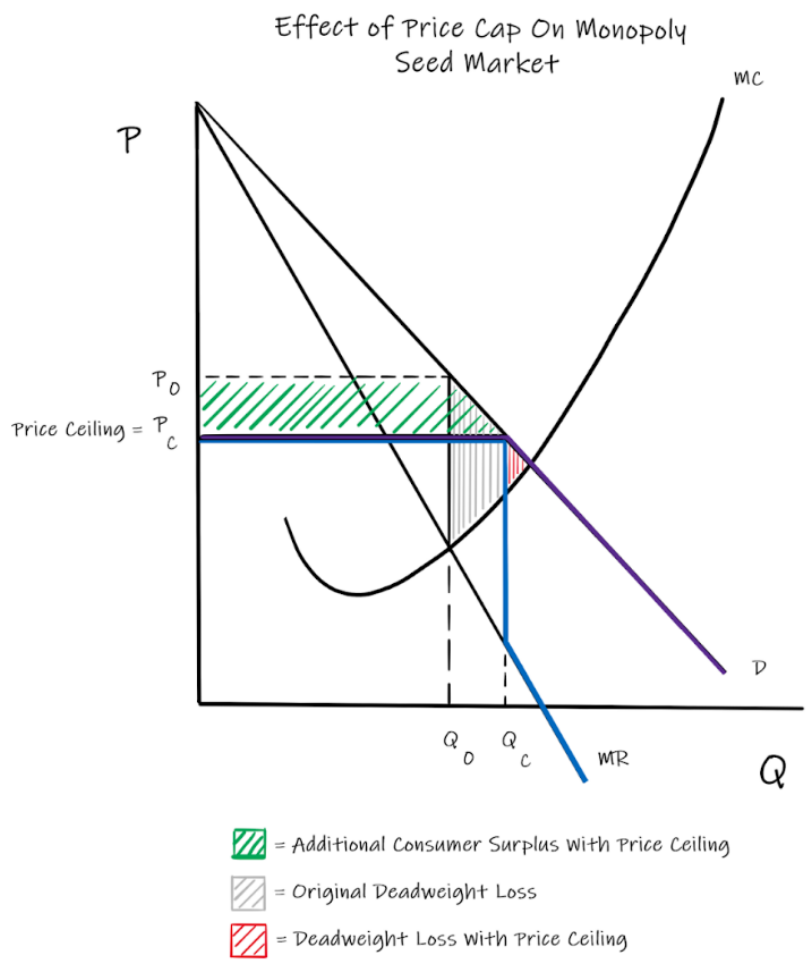

Figure 4. Effect of Price-Cap on Monopoly Seed Market

An alternate way to limit market power for the sake of consumer welfare is to decrease barriers of entry in the GM seed market. As patents are one of the largest barriers for many GM seed firms, their lifting should be considered. The reduction of market power over seeds may not be enough, however, as the genetic traits of seeds are heavily patented. In fact, the market concentration of genetic traits is higher than that of GM seeds themselves (OECD, 2018). Therefore, the limitation of utility patents, rather than GM plant patents (as commonly perceived) should be considered. Utility patents are different from plant patents, as it allows for the protection of unique DNA in GM crops, rather than simply the plants themselves. As well, they prohibit the replanting of seeds (whereas plant patents cannot, because they allow sexual reproduction of seeds as long as the seeds are not sold to others for planting) (Zhou, 2015). Therefore, the lifting of utility patents could prove to be effective in reducing market power, as it prevents monopolies from having full ownership over GMO genetics. A common concern to this solution is that patents are required to promote further innovation into GM technology, as GM companies rely on the "exclusivity" given to them to cover GM research expenses. So, a combination of a utility patent limitation and the maintenance of regular GM seed patents could prove useful in reducing market power.

As mentioned previously, global asymmetries and trade barriers due to the disapproval of GM crops overseas have resulted in the loss of many potential economic benefits from GM crops usage. Thus, a harmonization of international trade and approval of GM crops could be worthy of establishing. With widespread international adoption of HT and insect resistance in these crops, annual welfare gains could be approximately $\$ 10$ billion (Qaim, 2009). In addition to the welfare gain, consumers would see drastic decreases in GM crop prices of at least 13\% (Phillips, 2014) (Fig. 5). The implementation of this international diffusion of GM technology could, in turn, result in global 
competition, creating many more benefits for both firms and consumers. This includes expanded customer and consumer bases, lowered business production costs, and the reduction of "political risks", such as governmental interference in businesses (Ketchen et al., 2014). Bilateral trade agreements could also aid in the diffusion of GM technology, as they eliminate tariff and export barriers. However, certain countries, such as those in the EU, would only agree to these trade deals if adequate scientific research were carried out to ensure the safety of GM crops. Notably, one of the main reasons the EU continues to reject GM crops is to "protect human. . . health" (Papademetriou, 2014). Hence, this leads to suggestions for further research.

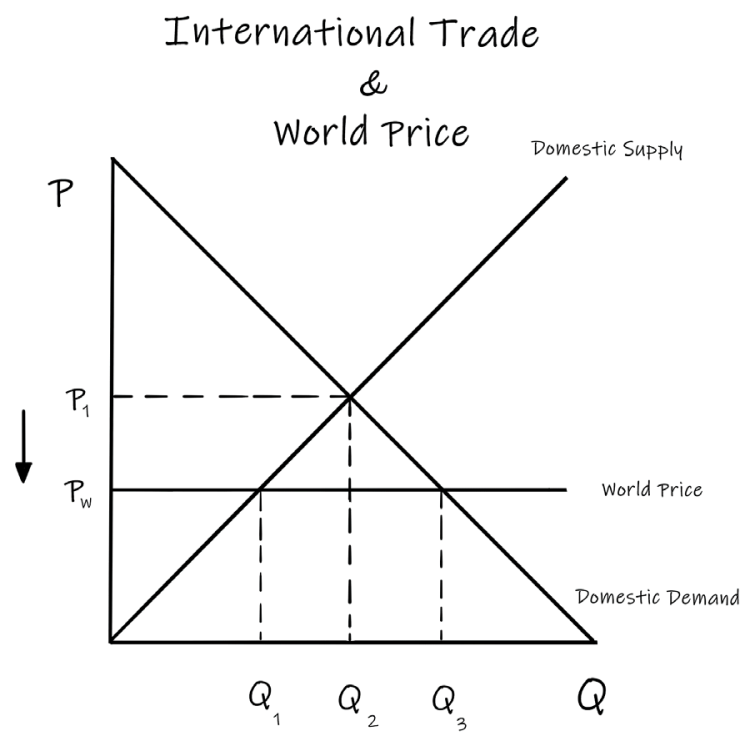

Figure 5. Effect of International Trade on Prices.

\section{Suggestions for Further Research}

To realize the economic benefits of an international diffusion on GM technology, scientific research and economic analyses must be conducted to determine the health repercussions of GM crops, as well as potential biosafety externalities. Further research can investigate the location of the socially optimal quantity in relation, and whether the market is in a positive or negative externality situation. If positive externalities are found, it could aid countries in the EU to make economically informed decisions to allow GM crops, enabling international trade, and realizing the economic benefits that come with it, as discussed earlier. Furthermore, studies may be conducted to more accurately calculate the Herfindahl-Hirschman Index (HHI) to measure the market concentration of all GM seeds. Many past studies have utilized methods such as the "four-firm concentration ratio" to estimate market concentration, but this method fails to "capture the relative size of different firms", meaning it cannot distinguish whether a market is shared equally by several large firms or if it is dominated by one firm; however, the HHI accounts for this problem (OECD, 2018). Additionally, more studies need to calculate the HHI for markets beyond commercial seed markets for increased accuracy, as in many developing countries, farmers use "farm-saved seed" or exchange GM seeds in sectors other than the commercial market. The OECD study has analyzed the HHI in a similar method as suggested, but, as it notes, it does not cover certain markets, such as the vegetable seed market, so further studies could fill this research gap. 


\section{Conclusion}

Evidently, the world is heavily dependent on the efficiency and productivity of GMOs to sustain the food supply and diminish global economic inequality. However, with patents, biosafety regulations, and trade barriers, many potential economic benefits of GM crops are not realized; sometimes, costs are even equal to the benefits received due to compliance fees and monopolized markets. Despite this, the former suggests agricultural and labor economies cannot afford a return to non-GM crops. Thus, a limit on GMO production is undesirable; rather, imposing more effective market regulations to decrease market power and promote global harmonization of GM crops could yield promising results for farmers and consumers. Market power could be limited by setting price caps on GM seed prices (as India has previously done), lifting utility patents, and conducting scientific research on the safety of GM crops to possibly encourage countries, like those in the EU, to agree to bilateral trade deals. A first step is to conduct further research into the potential biosafety externalities of GM crops in current markets and analyze the market concentration of GM seeds to determine the best way to reduce market power. Through this, GM crops could provide great economic benefits to farmers and consumers across the globe.

\section{Acknowledgments}

I would like to thank my advisor Aaron Giesbrecht for helping me with this project.

\section{References}

Bayer, J. C., Norton, G. W., \& Falck-Zepeda, J. B. (2010). Cost of Compliance with Biotechnology Regulation in the Philippines: Implications for Developing Countries. The Journal of Agrobiotechnology Management \& Economics, 13(1), 53-62. www.agbioforum.org/v13n1/v13n1a04-norton.htm.

Bhardwaj, M. (2018, January 12). Indian government caps GMO cotton price, cuts Monsanto seed royalties by 70 percent. Genetic Literacy Project. https://geneticliteracyproject.org/2016/03/11/indian-government-caps-gmocotton-price-cuts-monsanto-seed-royalties-70-percent/.

Brookes, G., \& Barfoot, P. (2020). GM crop technology use 1996-2018: farm income and production impacts. GM Crops \& Food, 11(4), 242-261. https://doi.org/10.1080/21645698.2020.1779574

Caruvana, D., \& Holton-Basaldua, C. A. (2013). Bowman v. Monsanto Company. Legal Information Institute. https://www.law.cornell.edu/supct/cert/11-796.

Coherent Market Insights. (2020, February 17). Genetically Modified Crops Market to Surpass US\$37.46 Billion by 2027. Coherent Market Insights. http://www.coherentmarketinsights.com/press-release/genetically-modified-cropsmarket-2825.

Fernandez-Cornejo, J., Wechsler, S., Livingston, M., \& Mitchell, L. (2014). Genetically Engineered Crops in the United States. SSRN Electronic Journal. https://doi.org/10.2139/ssrn.2503388

Hammer, M. (n.d.). The Economics of Genetically Modified Foods. Markrp. https://web.stanford.edu/ cbross/Markrp.html. 
James, C. (2013). Global Status of Commercialized Biotech/GM Crops: 2013. The International Service for the Acquisition of Agri-Biotech Applications (ISAAA).

https://www.isaaa.org/resources/publications/briefs/46/download/isaaa-brief-46-2013.pdf.

Ketchen, D., Short, J., Try, D., \& Edwards, J. (2014). Advantages and Disadvantages of Competing in International Markets. Mastering Strategic Management 1st Canadian Edition.

https://ecampusontario.pressbooks.pub/strategicmanagement/chapter/advantages-and-disadvantages-of-competingin-international-markets/.

Klümper, W., \& Qaim, M. (2014). A Meta-Analysis of the Impacts of Genetically Modified Crops. PLOS ONE, 9(11). https://doi.org/10.1371/journal.pone.0111629

Kruft, D. (2001, November). Impacts of Genetically-Modified Crops and Seeds on Farmers. The Agricultural Law Resource and Reference Center. https://pennstatelaw.psu.edu/ file/aglaw/Impacts of Genetically Modified.pdf.

Mullot, L. (2017). GM benefits and the future. Grains Research and Development Corporation. https://grdc.com.au/resources-and-publications/groundcover/groundcovertm-130-september-october-2017/gmbenefits-and-the-future.

National Research Council. (2010). Farm-Level Economic Impacts. In The Impact of Genetically Engineered Crops on Farm Sustainability in the United States (pp. 135-175). National Academies Press.

https://www.nap.edu/read/12804/chapter/5.

OECD. (2018). New evidence on market concentration. In Concentration in Seed Markets: Potential Effects and Policy Responses (pp. 115-163). OECD Publishing. https://www.oecd-ilibrary.org/sites/9789264308367-8en/index.html?itemId=/content/component/9789264308367-8-en.

Papademetriou, T. (2014, March 1). Restrictions on Genetically Modified Organisms: European Union. Restrictions on Genetically Modified Organisms: European Union | Law Library of Congress.

https://www.loc.gov/law/help/restrictions-on-gmos/eu.php.

Phillips, P. W. B. (2014, December 11). Economic Consequences of Regulations of GM Crops. Genetic Literacy Project. https://geneticliteracyproject.org/2014/12/11/economic-consequences-of-regulations-of-gm-crops/.

Qaim, M. (2009). The Economics of Genetically Modified Crops. Annual Review of Resource Economics, 1(1), 665-694. https://doi.org/10.1146/annurev.resource.050708.144203

Sally, M. (2016, March). Government snubs Monsanto, caps price of Bt cotton seeds. The Economic Times. https:/economictimes.indiatimes.com/news/economy/agriculture/government-snubs-monsanto-caps-price-of-btcotton-seeds/articleshow/51336331.cms?utm source=contentofinterest\&utm medium=text\&utm campaign=cppst.

Smyth, S. (2019, January 9). 25 years of GMO crops: Economic, environmental and human health benefits. Genetic Literacy Project. https://geneticliteracyproject.org/2018/04/06/25-years-of-gmo-crops-economic-environmental-andhuman-health-benefits/.

Whelan, A. I., \& Lema, M. A. (2017). A research program for the socioeconomic impacts of gene editing regulation. GM Crops \& Food, 8(1), 74-83. https://doi.org/10.1080/21645698.2016.1271856 
Yorobe, J. M., \& Quicoy, C. (2006). Economic Impact of Bt Corn in the Philippines. The Philippine Agricultural Scientist, 89(3), 258-267.

https://www.isaaa.org/programs/impact assessment of crop biotechnology/download/Economic\%20impact $\% 20$ of \%20Bt $\% 20$ corn $\% 20$ in $\% 20$ the $\% 20$ Philippines.pdf.

Zhou, W. (2015, August 11). The Patent Landscape of Genetically Modified Organisms. Science in the News. https://sitn.hms.harvard.edu/flash/2015/the-patent-landscape-of-genetically-modified-organisms/ . 